\title{
A review of numerical modelling of cyclones and tsunamis in the arabian sea by royal haskoningDHV
}

\begin{abstract}
Significant loss of life and damage to properties, ecosystems and marine facilities can occur due to various natural hazards such as cyclones and tsunamis. Modelling results are used for deriving robust design conditions for coastal and marine structures and facilities. The modelling results are also used for emergency planning and decisionmaking to estimate potential loss of life, damage to properties and marine facilities and to develop rescue and mitigation measures and plan clean-up operations. Royal HaskoningDHV has developed regional hydrodynamic and wave models covering the Arabian Sea to address these issues. A total of 30 major cyclones were initially identified in the Arabian Sea since 1945 from where 13 major cyclones were simulated. The tsunami modelling was carried out on an earthquake along the Makran Fault Line in 1945. Sample results from these modelling studies are presented in this paper for illustration purposes. The models could be used to simulate any cyclone and tsunami generated anywhere within the Arabian Sea. The methodology described in this article for modelling cyclones and tsunamis in the Arabian Sea could be applied to simulate these natural hazards at other sites around the world.
\end{abstract}

Volume I Issue 3 - 2017

\author{
Sarker MA \\ Principal Engineer, Royal HaskoningDHV, UK
}

Correspondence: Sarker MA, Principal Engineer, Royal HaskoningDHV, Rightwell House, Bretton, Peterborough PE3 8DW,UK, Email zaman.sarker@rhdhv.com

Received: July 26, 2017| Published: September 20, 2017

Keywords: Numerical modelling, Cyclones, Tsunamis, Extreme waves, Storm surge, Port development, Arabian sea

\section{Introduction}

Cyclones and tsunamis are two of the most harmful natural hazards and can cause significant loss of life and damage to properties, ecosystems and marine structures and facilities. Climate change is worsening the situation. Given the above risks, Royal Haskoning DHV has developed regional tidal hydrodynamic and wave models covering the Arabian Sea to investigate hazards from cyclones and tsunamis and to support their project work in the region. Cyclone and tsunami modeling results are used for deriving robust design conditions for coastal and marine structures and facilities. Cyclone and tsunami modelling results are also used for emergency planning and decision-making to estimate potential loss of life, damage to properties and marine facilities and to develop rescue and mitigation measures and plan clean-up operations. Sample results of cyclones (waves and surge) and tsunamis from the modelling studies carried out by Royal Haskoning DHV are presented in this article for illustration purposes only. The model could be used to simulate any cyclone and tsunami generated anywhere within the Arabian Sea. The methodology described in this article for modelling cyclones and tsunamis in the Arabian Sea could also be applied to simulate cyclones and tsunamis at other sites around the world.

\section{Formation of cyclones}

Tropical cyclones (also known as hurricanes or typhoons) are associated with warm and moist air and hence they form only over warm ocean waters near the equator. The warm and moist air rises causing an area of lower pressure beneath. Cooler air moves into the lower pressure area and becomes warm and moist and rises too. When the warm and moist air rises, it cools down and forms clouds. The whole system of clouds and winds spins and grows and is fed by ocean's heat and evaporated water continuously. An ocean temperature of at least $26.5^{\circ} \mathrm{C}$ spanning through a depth of at least $50 \mathrm{~m}$ is required for the formation and growth of a cyclone. ${ }^{1}$ Cyclones that form north of the equator spin counter-clockwise whereas cyclones south of the equator spin clockwise due to the difference in Earth's rotation on its axis. Cyclones are associated with high-pressure gradients and consequently generate strong winds and storm surges. The destruction from a tropical cyclone depends on its intensity, size and location.

\section{Formation of tsunamis}

A tsunami (also known as a seismic sea wave) is a series of water waves (similar to shallow water waves) in a water body caused by the abrupt displacement of a large volume of water initially resembling a rapidly rising tide. A tsunami is generated by underwater earthquakes, landslides, fault breaks (ruptures), volcanic eruptions and other underwater explosions (such as the detonation of nuclear devices), glacier calving, impact of objects from outer space (such as meteorites, asteroids, comets) and other disturbances in water. Ninety (90) percent or more of historical tsunamis in the world have been generated by earthquakes in the sea and coastal regions. Generally larger and shallower hypocentre earthquakes cause larger tsunamis. ${ }^{2}$

\section{Damage from cyclones and tsunamis}

Significant loss of life and damage to properties, ecosystems and marine facilities can occur due to cyclones and tsunamis. They also impose significant risks during construction and operation of sea ports, oil terminals \& jetties, offshore exploratory drilling rigs and offshore oil extraction rigs. Furthermore, these natural hazards put lives and properties in coastal areas at greater risks. Very strong winds during a cyclone and very high tides during a tsunami may damage installations, dwellings, transportation and communication systems, trees etc. and cause fires resulting in considerable loss of life, damage to properties and ecosystems. Destruction of transportation or communication infrastructures hampers clean-up and rescue efforts. Heavy and prolonged rain and storm surges due to cyclones and high tides during a tsunami may cause floods and submergence of low 
lying areas and can lead to mudslides and landslides in mountainous areas causing loss of life and property. The resulting floods, standing water and coastal inundation pollute drinking water sources and spread diseases leading to outbreak of epidemics. Cyclones and tsunamis also cause secondary damage from floating debris, trees and vessels, sediment erosion and deposition and spreading of fire. During the last two centuries, tropical cyclones have been responsible for the deaths of about 1.9 million people worldwide. ${ }^{3}$ It is estimated that 10,000 people per year perish due to tropical cyclones. ${ }^{3}$ For example, Bangladesh is especially vulnerable to tropical cyclones with around 718,000 deaths from them in the past 50 years. ${ }^{4}$ An estimated 138,000 people were killed in Bangladesh by the 1991 Cyclone $^{.5}$ The deadliest tropical cyclone in Bangladesh was the 1970 Bhola Cyclone, which had a death toll of anywhere from 300,000 to 500,000 lives. $^{3}$ As reported in, ${ }^{6}$ the 1960 Valdivia earthquake $\left(M_{w}\right.$ 9.5), 1964 Alaska earthquake ( $\left.M_{w} 9.2\right), 2004$ Indian Ocean earthquake $\left(\mathrm{M}_{\mathrm{w}}\right.$ 9.2) and 2011 Tōhoku earthquake $\left(\mathrm{M}_{\mathrm{w}}\right.$ 9.0) are recent examples of powerful megathrust earthquakes that generated tsunamis (known as teletsunamis or distant tsunamis) that can cross entire oceans. The 2004 Indian Ocean tsunami was among the deadliest natural disaster in human history with at least 230,000 people killed or missing in 14 countries bordering the Indian Ocean. The 2011 tsunami in Japan resulted to 15,894 deaths, 6,152 injured and 2,562 people missing. The 2011 tsunami damaged many buildings, dams, bridges, nuclear power stations and many other infrastructures. The World Bank's estimated economic cost due to the 2011 tsunami was US\$235 billion, making it the costliest natural disaster in world history. As reported in, ${ }^{7}$ deaths from the 1945 earthquake in the Makran Fault that generated tsunamis along the coastlines of Iran and Pakistan were reported to be as many as 4,000 people. Furthermore, the tsunami caused catastrophic damage to properties and other coastal facilities.

\section{Arabian sea regional models of royal haskoningDHV}

Royal HaskoningDHV has developed regional tidal hydrodynamic and wave models (using the MIKE21/3 software) covering the Arabian Sea to investigate these natural hazards and support their project work in the region. The regional model covers the coastlines of six countries i.e. Yemen, Oman, UAE, Iran, Pakistan and India (Figure 1). A flexible (triangular) mesh was used with variable mesh size distribution to obtain accuracy in the model results. The models have been used to assess cyclones and tsunamis within the Arabian Sea. Cyclone modelling has concentrated on 13 major cyclones since 1945 and the tsunami modelling on an earthquake along the Makran Fault Line (offshore from the coastlines of Iran and Pakistan) in 1945. Sample results from these modelling studies are presented in this article for illustration purposes only.

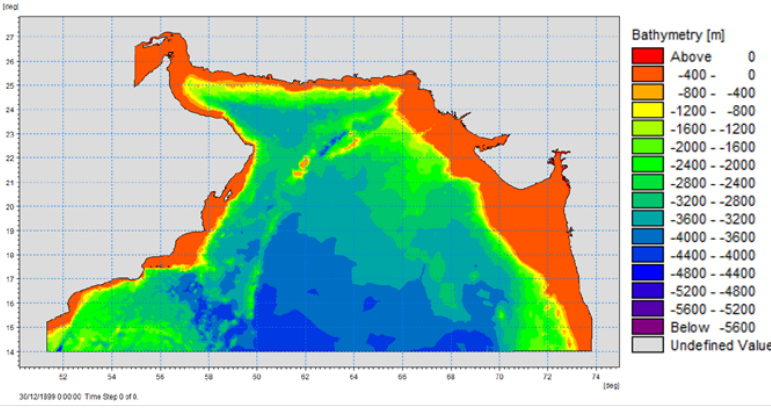

Figure I Model extent and bathymetry.

\section{Cyclones modelling by royal haskoningDHV}

Royal HaskoningDHV has developed a Regional Cyclone Model for the Arabian Sea using the MIKE21/3 software. The cyclone model can be used to simulate both waves and surges for cyclones passing through the Arabian Sea. The MIKE21 Spectral Wave (SW) Model was used to simulate the cyclone waves. ${ }^{8}$ The fully spectral formulation of the SW model is based on the wave action conservation equation, where the directional-frequency wave action spectrum is the dependent variable. The MIKE21/3 Flow Model FM was used to simulate the cyclone surge. ${ }^{9}$ The model is based on the numerical solution of the two/three-dimensional incompressible Reynolds averaged Navier-Stokes equations invoking the assumptions of Boussinesq and of hydrostatic pressure. Thus, the model consists of continuity, momentum, temperature, salinity and density equations. In a recent study for a site in southern Oman, a total of 30 major cyclones were initially identified to have crossed the Arabian Sea since 1945 and affected the Omani coastline. A total of 13 cyclones were selected from this pool of 30 cyclones for the study based on a combination of severity (wind speed and, central pressure and diameter) and the proximity to site i.e. severe events were selected regardless of distance from the site while less severe events were only selected if they made land fall within $300 \mathrm{~km}$ of site. Tracks and pressure fields of the selected cyclones were obtained from the Joint Typhoon Warning Center (JTWC), USA. ${ }^{10}$ Tracks of some major cyclones in the Arabian Sea are shown in Figure 2. The MIKE21 Toolbox ${ }^{11}$ was used to derive wind and pressure fields from the cyclone tracks and central pressures. The tool allows users to compute wind and pressure data due to tropical cyclone (hurricane or typhoon). Several cyclone parametric models are included in the tool such as Young and Sobey model (1981), Holland - single vortex model (1981), Holland - double vortex model (1980) and Rankine vortex model ${ }^{11}$ All the six input parameters required by the Young and Sobey model (i.e. time, track, radius to maximum wind speed, maximum wind speed, central pressure and neutral pressure) were available for the study and this was, therefore, used to generate the cyclonic wind and pressure fields. The other models require some additional parameters (such as Holland parameter B and Rankine parameter X) that need to be calculated using empirical relationships which add further uncertainty to the generated wind and pressure fields and were, therefore, not used for the study.Figure 3 shows an example of wind and pressure fields. These wind and pressure fields were used to drive the cyclone wave and surge models described later.

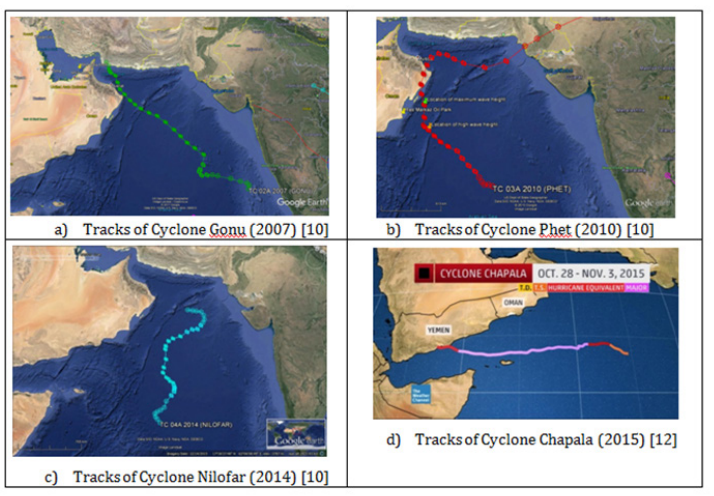

Figure $\mathbf{2}$ Tracks of some major cyclones in the Arabian Sea.

The cyclone model was validated using observed data. The methodology, model setup, model validation, model results and 
findings from the numerical modelling of various cyclones are presented in. ${ }^{7-16}$ Typical model results of cyclonic waves are illustrated in Figure 4-6. Cyclone Phet (2010) generated a maximum significant wave height of about $13 \mathrm{~m}$ in the Arabian Sea and about $4 \mathrm{~m}$ in the Gulf of Oman ${ }^{7}$ whereas Cyclone Gonu (2007) generated maximum significant wave height of about $15 \mathrm{~m}$ in the Arabian Sea and about $9 \mathrm{~m}$ in the Gulf of Oman. The maximum significant wave height of $12.8 \mathrm{~m}$ during Cyclone Nilofar (2014) was found in the centre of the Arabian Sea and in contrast to Cyclones Gonu and Phet the height of waves reaching the Omani coast was limited. ${ }^{16}$ A maximum significant wave height of $19.2 \mathrm{~m}$ was found during Cyclone Chapala (2015) in the middle of the Arabian Sea and that the height of waves reaching the Omani coast was also limited. It is noted that neither Nilofar nor Chapala approached close to the Omani coast (Figure 2). Typical model results of cyclonic surges are illustrated in Figure 7 \& Figure 8 . The highest surge of approximately $1.0 \mathrm{~m}$ was found at the northern part of the Masirah Island during Cyclone Phet. ${ }^{7}$ Cyclone Gonu (2007) generated maximum surge of approximately $1.0 \mathrm{~m}$ in the middle of the Arabian Sea and of approximately $0.5 \mathrm{~m}$ at Muscat. The maximum surge of approximately $0.8 \mathrm{~m}$ was found during Cyclone Nilofar (2014). ${ }^{16}$ During Cyclone Chapala (2015), the highest surge of $0.74 \mathrm{~m}$ occurred close to the cyclone track. Surge in the Gulf of Aden was $0.70 \mathrm{~m}$ during this cyclone. Cyclone Chapala generated about $0.60 \mathrm{~m}$ negative surge in the Gulf of Aden.
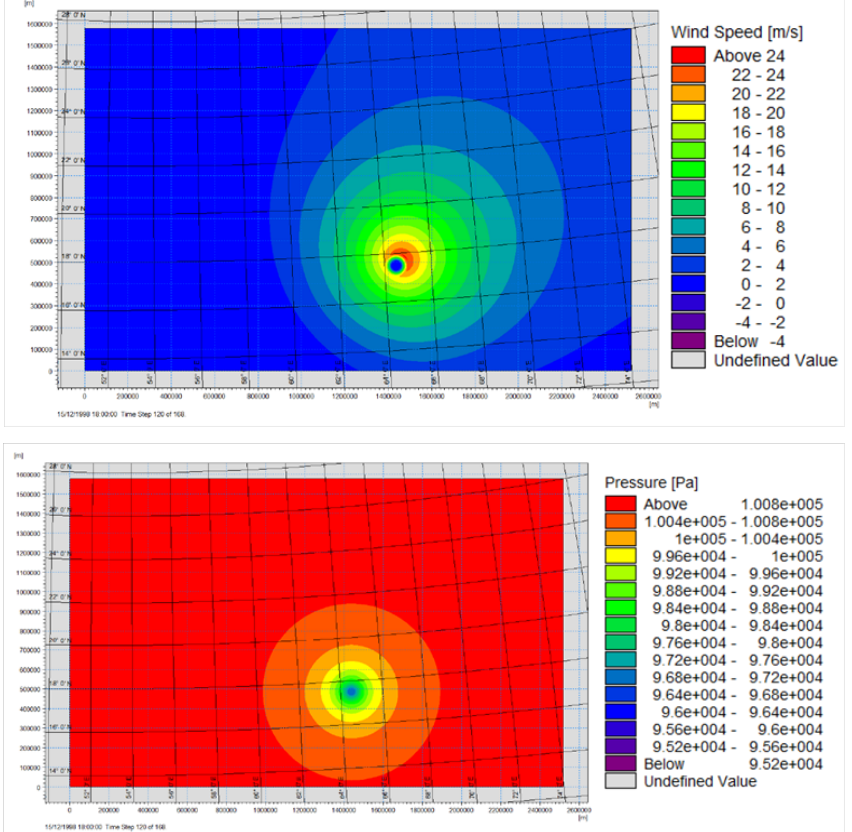

Figure 3 Cyclone wind and pressure fields [TC 08A, 1998].A: Cyclone wind fields; B: Cyclone pressure fields.

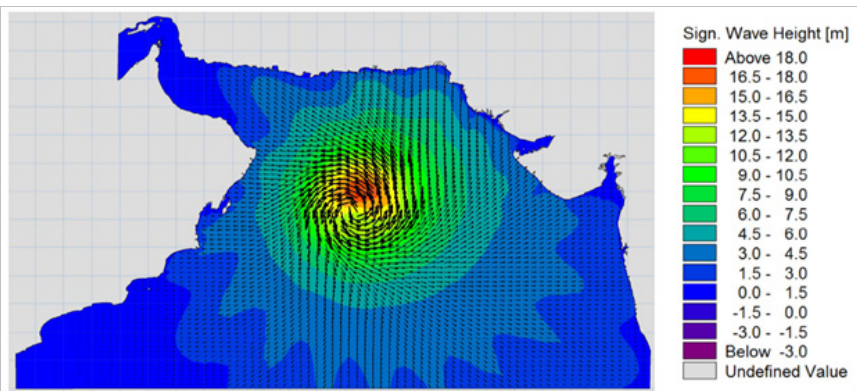

Figure 4 Waves heights and directions of cyclone gonu (2007) at a particular time-step.

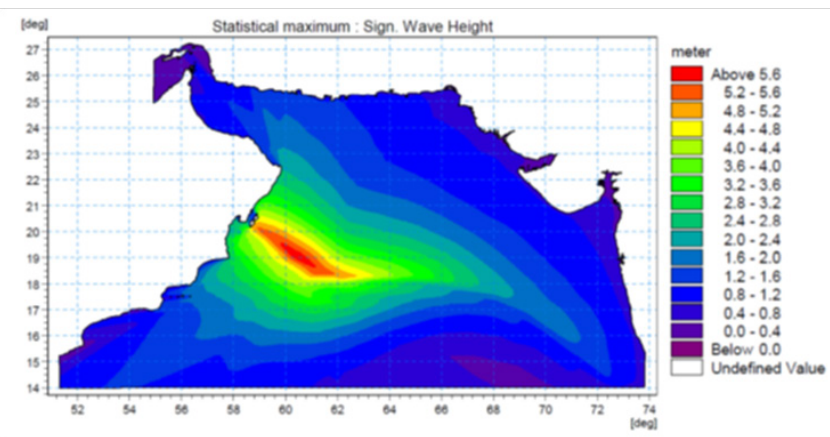

Figure 5 Maximum significant wave height $(\mathrm{m})$ over the entire duration of cyclone TC 06A (1992)

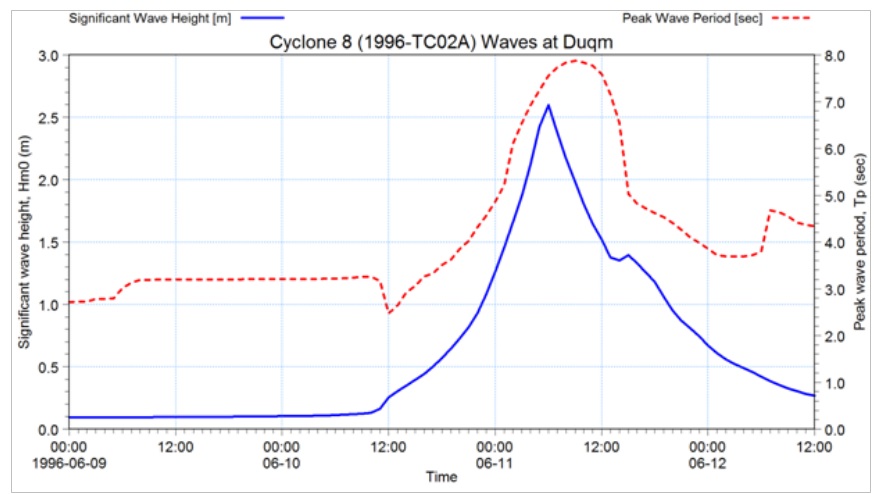

Figure 6 Time-series of significant wave heights and peak wave period of Cyclone TC 02A 1996

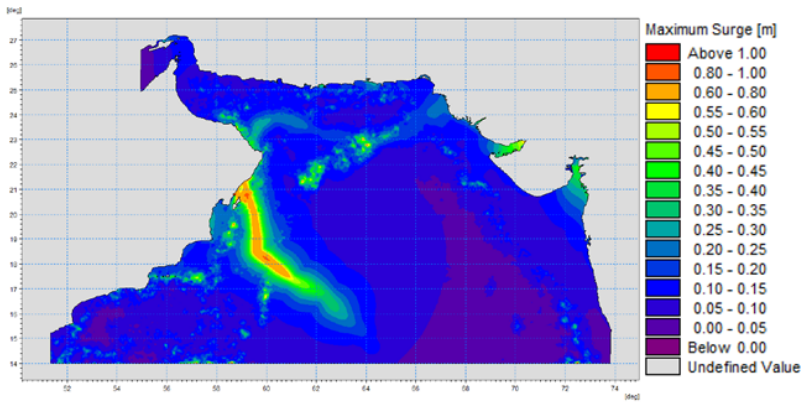

Figure 7 Maximum surge during the entire duration of cyclone phet (2010).

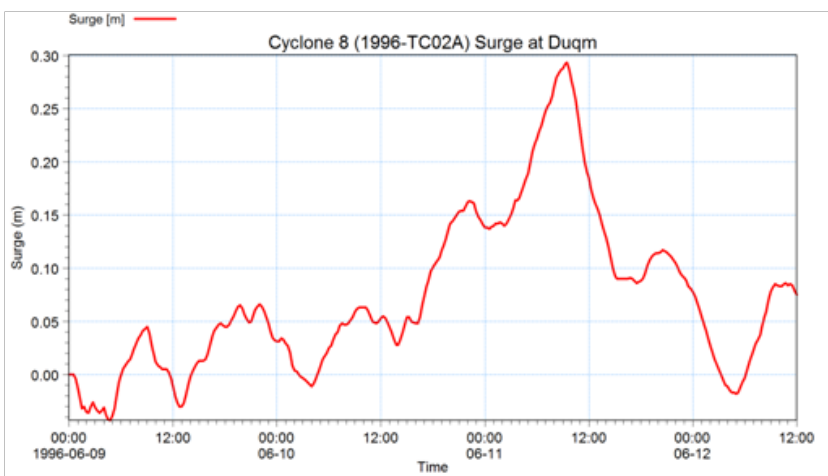

Figure 8 Time-series of surge of Cyclone TC 02A [1996].

\section{Tsunamis modelling by royal haskoningDHV}

Royal HaskoningDHV has developed a Regional Tsunami Model for the Arabian Sea using the MIKE21/3 Flow Model FM 
software. ${ }^{9}$ The modelling system is based on the numerical solution of the two-dimensional shallow water equations - the depth-integrated incompressible Reynolds averaged Navier-Stokes equations. Thus, the model consists of continuity, momentum, temperature, salinity and density equations. A flexible (triangular) mesh was used with variable mesh size distribution to obtain accuracy in the model results. The model can be used to simulate the propagation of tsunami waves and to predict their height and forward velocity within the Arabian Sea region. The 1945 Baluchistan Earthquake in Pakistan occurred at 5:26 PST on 28 November 1945 along the Makran Fault with a magnitude of 8.1. The earthquake's epicenter was $97.6 \mathrm{~km}$ southsouthwest of Pasni in Baluchistan (Pakistan) and the resulting tsunami caused damage along the Makran coastal region. The Delft Dash Board of Deltares ${ }^{17}$ was used to generate the initial rise in sea surface due to the movement along the Makran Faults. The initial rise in sea surface (Figure 9) was then used in the regional model to simulate the propagation of the tsunami waves. The tsunami model was validated using information from public domain. The methodology, model setup, model validation, model results and findings from the numerical modelling of the tsunami are presented in. ${ }^{7-13}$ Typical model results of tsunami wave propagation are illustrated in Figure $10 \&$ Figure 11. The modelling studies showed an initial rise in sea surface of about $2 \mathrm{~m}$ due to the movement along the Makran Fault Line as shown in Figure 9. The propagation of tsunami waves over time was extracted from model results as illustrated in Figure 8. The model results indicate that it will take approximately 15 minutes for the tsunami to reach Pasni (Pakistan), less than 30 minutes to reach Muscat and less than one hour to reach Masirah Island (Oman). The coastal areas north of the Makran Fault Line are the worst affected due to their close proximity to the fault. A rise in water level of 4.3 $\mathrm{m}$ was found at Pasni and $0.22 \mathrm{~m}$ at Muscat. The coastal areas north of the Makran Fault Line are worst affected by tsunami currents with maximum current speeds up to $3.2 \mathrm{~m} / \mathrm{s}^{\text {predicted. }}{ }^{7}$

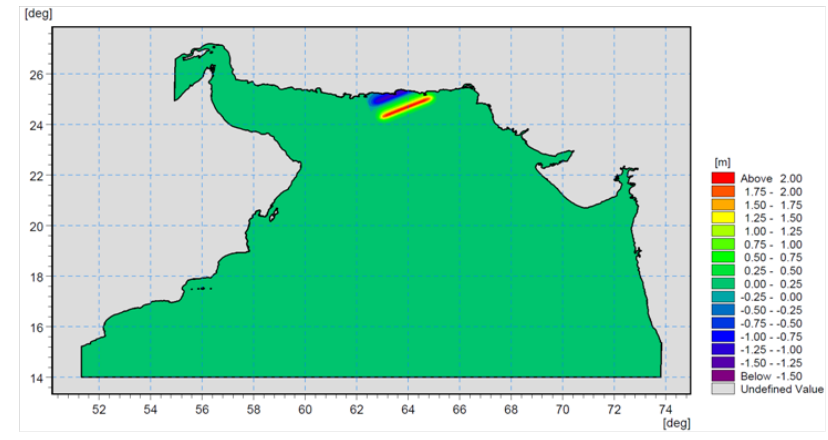

Figure 9 Initial rise in sea surface during the 1945 tsunami.

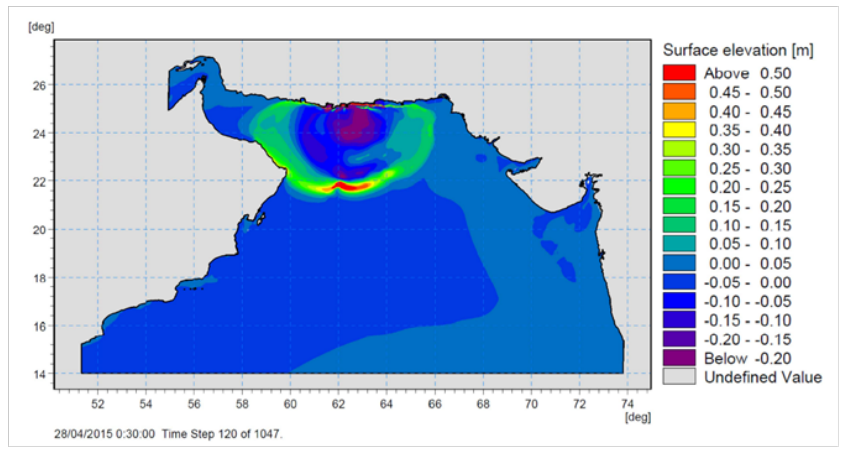

Figure 10 Tsunami waves after 30 minutes of the 1945 earthquake in the makran fault.

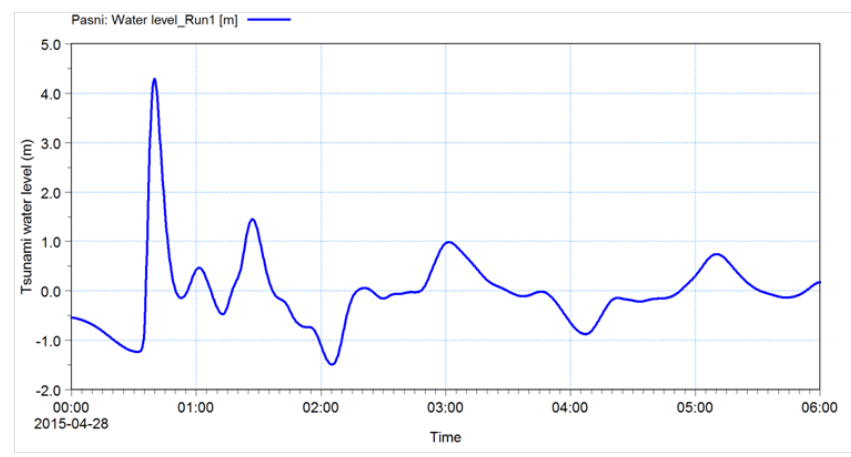

Figure I I Time-series of 1945 tsunami water levels at pasni (Pakistan).

\section{Application of modelling results}

Cyclone and tsunami model results provide valuable information at all stages of a project including planning, design, environmental impact assessment, construction, operation, and de-commissioning. The model results can also be used in emergency planning and decisionmaking to estimate potential loss of life, damage to properties and marine facilities and to develop mitigation measures and plan cleanup operations. The cyclone and the tsunami models are key tools for deriving robust design conditions for coastal and marine structures and facilities. The models provide input conditions to physical models in a laboratory to test structural stability and overtopping rates. The model results can also be used to predict flood extents and depths.

\section{Recommended design considerations}

The potential impact of a cyclonic/tsunami event on the design of coastal and marine facilities may be summarised as follows:

1. The foreshore will be subjected to flooding as the cyclone/ tsunami waves and surge approach.

2. Facilities located on the landward slope are at risk from cyclone/tsunami wave run-up and surge.

3. Shoaling results in an increase in water levels and stronger currents inshore and the measures will be required to protect structures from scouring of the foreshore and sea bed.

4. Cyclones generate high wind speeds and, therefore, wind loads on structures should be calculated based on cyclone analysis.

These impacts are in addition to the widespread flooding that can occur from the high rainfall associated with a cyclone.

\section{Cyclone and tsunami risk reduction measures}

Damage due to a cyclone/tsunami depends on the strength and proximity of the cyclone/tsunami as well as local bathymetry and topography and location of people, structures and facilities. It is almost impossible to fully protect people and settlements from major strong cyclones/tsunamis events. However, various soft and hard measures (independently or in combination) could be adopted to reduce fatalities and damage to key infrastructure. Some potential measures to reduce the risk of damage from major cyclone/tsunami events are highlighted below:

Appropriate awareness and understanding among the general public will reduce death toll;

Mitigation plans and evacuation and rescue preparedness by responsible authorities will reduce damage and death toll; 
a. Cyclone/tsunami risk assessment, flood risk and inundation hazard maps, detection system, early warning system and realtime observation system are of great importance to save lives and reduce damage.

b. Cyclone/tsunami shelters are of great use for people to flee (such as those in Bangladesh).

c. Developing artificial forest such as mangroves and casuarinas of appropriate width behind the shoreline will reduce cyclone/ tsunami wave energy.

d. Maintaining natural sand dunes.

e. Regulations for development in the coastal zone.

f. Saline embankments to prevent salt-water entering into fertile lands.

g. Raising ground levels of important structures and facilities such as warehouses, terminals and quays will reduce risk to these being flooded.

h. Constructing cyclone/tsunami defence structures such seawalls, dykes, gates, nearshore breakwaters and offshore barriers will reduce risk and damage. However, these structures are huge and are very expensive.

For major coastal infrastructure, the adoption of appropriate design parameters, a proper assessment of structural loads, forces and stability in combination with a detailed understanding of cyclone/ tsunami processes will reduce the level of damage resulting from these events. Furthermore, physical modelling of major coastal and marine structures and mooring systems to investigate their stability under severe conditions will be helpful to reduce damage due to cyclones/tsunamis.

\section{Conclusion}

This article illustrates how tidal hydrodynamic and wave models can be used to simulate the impacts of cyclones and tsunamis on coastal developments and facilities. Although the emphasis has been on modelling these processes within the Arabian Sea, the methodology outlined in the article could be applied to sites within other regions that are affected by these natural hazards. The study work described in this paper has used modelling to hindcast the impact of cyclones and tsunamis in order to derive extreme conditions for design. Many organisations have developed real-time cyclone and tsunami forecasting systems which provide advanced warning of the impact of these events. These models play a vital role in preventing or minimizing loss of life and damage to assets.

\section{Acknowledgement}

The author would like to thank Royal HaskoningDHV (an independent, international engineering and project management consultancy company, www.royalhaskoningdhv.com) for permission to publish this article. Special thanks to Mr. Alec Sleigh (Technical Director, Maritime Sector of Royal HaskoningDHV UK) who carried out an internal review of the paper. For more details on this article and other numerical modelling work carried out by Royal HaskoningDHV worldwide, please contact Dr Sarker (email zaman.sarker@rhdhv. com).

\section{Conflict of interest}

None.

\section{References}

1. Tropical cyclogenesis. 2017.

2. PIANC.Mitigation of Tsunami Disasters in Ports. MarCom report. 2010;112(2010).

3. Effects of tropical cyclones. 2017.

4. Ubydul Haque, Masahiro Hashizume, Korine N Kolivras, et al. Reduced death rates from cyclones in Bangladesh: what more needs to be done. Bulletin of the World Health Organization. 2012;90(2):150-156.

5. 1991 Bangladesh Cyclone. 2017.

6. Tsunami; 2017.

7. Sarker MA, Sleigh AJ. Cyclone and Tsunami Hazards in the Arabian Sea-A Numerical Modelling Case Study by Royal HaskoningDHV. Journal of Shipping and Ocean Engineering. 2015;5(2015):242-254.

8. MIKE21 Spectral Waves User Guide. DHI Software, Denmark; 2007.

9. MIKE21 Flow Model FM User Guide. DHI Software, Denmark; 2007.

10. Joint Typhoon Warning Center (JTWC). US Department of Defense Agency, USA; 2007.

11. MIKE21 Toolbox User Guide. DHI Software, Denmark; 2007.

12. Jon Erdman. Cyclone Chapala a Rare. Destructive Landfall in Yemen. Weather Company, USA; 2017.

13. Sarker MA. How hydrodynamic and wave models can be used to simulate the impacts of cyclones, tsunamis and oil spills on coastal developments. International Journal for Port Management (World Port Development). 2015;15(3):37-39.

14. Sarker MA. Numerical Modelling of Cyclone Nilofar in the Arabian Sea. World Port Development. 2016;16(4):37-40.

15. Sarker MA. Numerical Modelling of Major Cyclonic Waves and Surge at Duqm (Oman) since 1945. World Port Development. 2017;17(5):38-40.

16. Sarker MA. Cyclone Hazards in the Arabian Sea-A Numerical Modelling Case Study of Cyclone Nilofar. Water and Environment Journal. 2017;31(2):284-295.

17. Tom Hijnekamp, Dianne den Hamer, Hans van Meerten. Technical paper: Site investigation based on return flow in HDD. Great Southern Press, Australia; 2017. 